\title{
Caudate nuclear infarction with attention disorder that requires differentiation from dementia: a case report
}

Ishida Tetsuro 1, $2^{*}$

${ }^{1}$ Hokujinkai ISHIBASHI Hospital, Nagahashi, Otaru, Japan.

${ }^{2}$ Department of Neuropsychiatry School of Medicine, Sapporo Medical University, Chuo-ku, Sapporo, Japan.

${ }^{*}$ Corresponding author: Ishida Tetsuro. Ishibashi Hospital 3-7-7 - Nagahashi. Zip Code: 047-0036 - Japan. Phone: +81-134-25-6655. E-mail: teturoisida@yahoo.co.jp.

Research Ethics Committee Approval (if necessary): We declare that the patient approved the study by signing an informed consent form and the study followed the ethical guidelines established by the Declaration of Helsinki.

Received on: Jul 19, 2021. Accepted on: Mon X, 2021. Available online: Mon X, 2021.

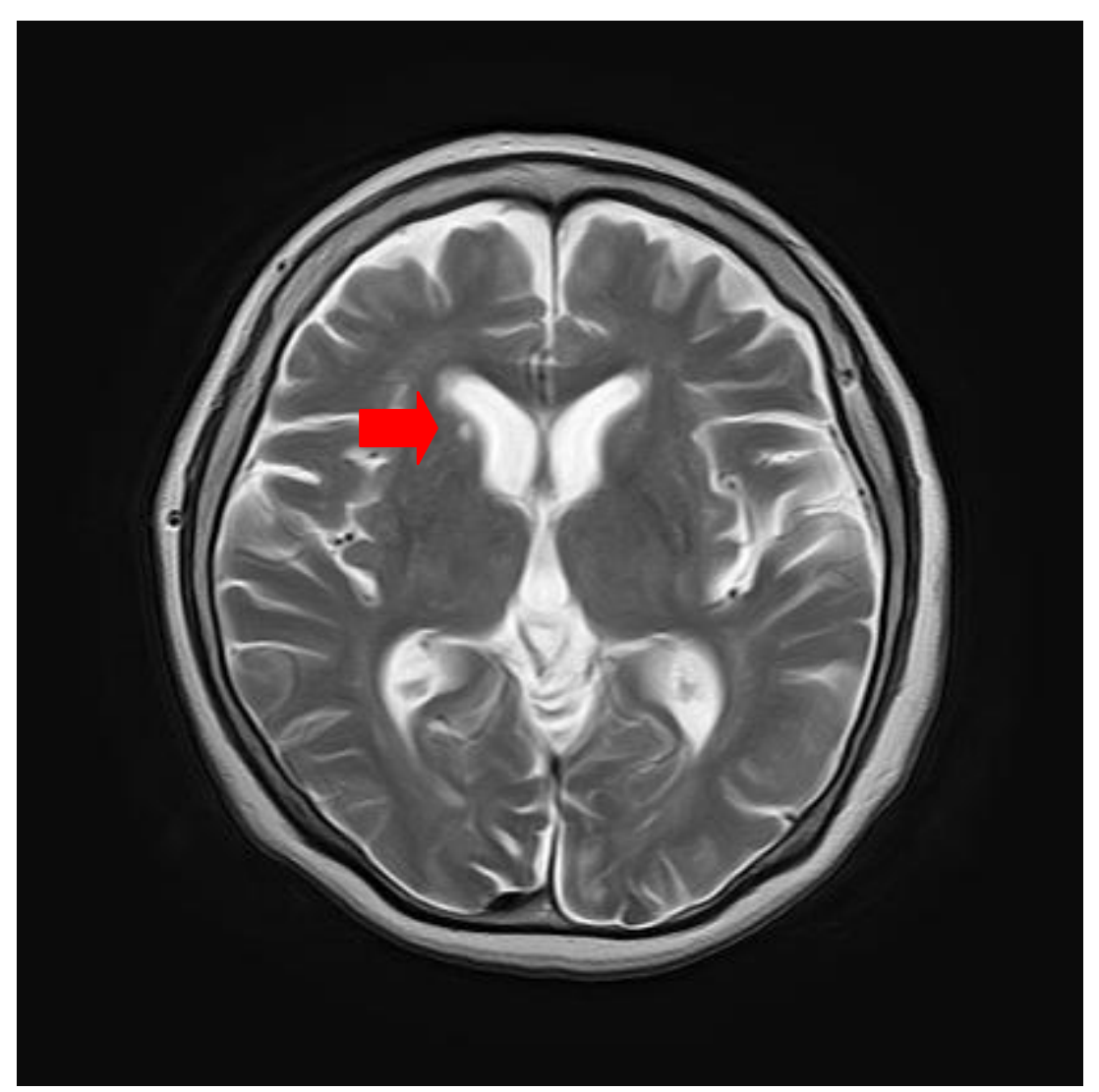

Figure 1. MRI exemplify a right caudate nucleus infarction (red arrow).

An 85-year-old woman consulted our hospital for forgetfulness. Although she is old, she has been living alone for a long time and has been able to take care of herself. However, she suddenly lost her concentration for three months. Her 
magnetic resonance imaging (MRI) of head showed no hippocampal or cortical atrophy suggestive of Alzheimer's disease but a right caudate nucleus infarction (Figure 1).

Her neurological examination showed no memory impairment but attention impairment. After that, Memantine (5 mg/day) was started, and occupational therapy which envisions her daily life gradually reduced her attention disorders. Now she is living well at home with the help of home helpers.

Cerebral small vessel disease (SVD) in the strategic white matter area is more associated with higher brain dysfunction than large lesions in other areas [1]. In particular, subcortical stroke including the caudate nucleus is known to cause attention disorders [2]. This case is a right caudate nucleus infarction, but it is known that cerebral hemorrhage in the right caudate nucleus also causes higher brain dysfunction such as memory impairment and attention disorder. This case corresponds to strategic single infarct dementia according to the diagnostic criteria of the National Institute of Neurological Disorders and Stroke International Institute (NINDS-AIREN), which classifies vascular dementia [3].

We need to pay attention to her appearance of memory loss, depressive symptoms and Parkinsonism. We should also pay attention to higher brain dysfunction due to SVD in the care of forgetfulness in the elderly.

\section{References}

[1] Biesbroek JM, Weaver NA, Biessels GJ. Lesion location and cognitive impact of cerebral small vessel disease. Clin Sci (Lond). 2017 Apr 25;131(8):715-728. doi: 10.1042/CS20160452.

[2] Liu J, Wang C, Diao Q, Qin W, Cheng J, Yu C. Connection disruption underlying attention deficit in subcortical stroke. Radiology. 2018 Jul;288(1):186-194.

[3] Chui HC, Mack W, Jackson JE, Mungas D, Reed BR, Tinklenberg J, Chang FL, Skinner K, Tasaki C, Jagust WJ. Clinical criteria for the diagnosis of vascular dementia: a multicenter study of comparability and interrater reliability. Arch Neurol. 2000 Feb;57(2):191-6. doi: 10.1001/archneur.57.2.191.

Conflict of interest: The author declares no conflicts of interest associated with this manuscript. The patient has provided permission to publish these features including her examination data and imaging findings of her case, and the identity of the patient has been protected.

Acknowledgements: We thank Drs. KAWANISHI Chiaki and UKAI Wataru and MURAYAMA Tomonori and KOBAYASHI Seiju and SHIRASAKA Tomonobu for helpful discussions and comments on the manuscript. 
Funding: None.

How to cite this article: Tetsuro I.

Caudate nuclear infarction with attention disorder that requires differentiation from dementia: a case report. Brazilian Journal of Case Reports. 2021 Jul-Sep; 01(3):38-40. 